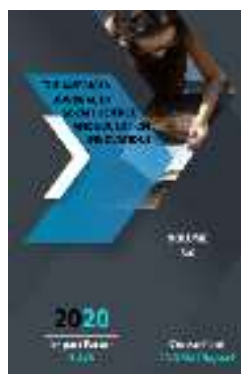

\title{
Socio-Psychological Properties Of Protection Of Adolescents From Negative Information Attacks
}

\author{
Nurullaev Adkham Akhmedovich \\ Basic Doctoral Student Of The Academy Of The Armed Forces Of The Republic Of Uzbekistan, \\ Lieutenant Colonel, Uzbekistan
}

\begin{abstract}
Journal Website: http://usajournalshub.c om/index,php/tajssei

Copyright: Original content from this work may be used under the terms of the creative commons attributes 4.0 licence.
\end{abstract}

\section{ABSTRACT}

As you know, youth determines the development of society and is one of the most significant tasks in its study as a "force" influencing its future development. The article highlights the socio-psychological aspects of protecting the youth of Uzbekistan from the impact of a destructive information attack. It also noted the presence of destructive information in the political, economic, cultural and social spheres and measures to protect against them.

\section{KEYWORDS}

Information, society, personality, subjectivity, computer games, acceleration, Internet sites, unlimited "no filter", teenager, psychological impact, self-esteem, self-control, psychological defense.

\section{INTRODUCTION}

The issue of youth is one of the most studied issues in all societies. Given that young people in Uzbekistan make up more than $60 \%$ of the total population, it is important to study any issue related to youth. Article 5 of the Law of the President of the Republic of Uzbekistan dated September 14, 2016 No. 406 "On State Youth Policy" stipulates that to bring up with confidence and views". So, protecting today's youth from information attacks is an important socio-cultural issue.

In this regard, the President of the Republic of Uzbekistan Shavkat Mirziyoev in his congratulatory message to the youth of Uzbekistan on the occasion of Youth Day on June 29, 2020 said: Along with many positive processes in our social life, the spiritual threats aimed at capturing the hearts and minds of the younger generation are 
becoming increasingly dangerous. In such a complex situation, our most urgent task is to protect our children from harmful influences, to always be vigilant and cautious. We will resolutely continue the great work we have begun to bring up our youth in the spirit of love and devotion to our Motherland, the ideas of independence, to realize their talents and abilities, their noble aspirations. In our society, the constant improvement of the spiritual and enlightenment level of the population, especially our young men and women, is of paramount importance" [1].

The term "information" is derived from the Latin word informatio, which means to explain, express, explain the content of the work, but also means the essence of some information, some evidence of knowledge, etc. [2]. From the point of view of materialist philosophy, information is an informationbased reflection of the material world. Information (data) is a form of representation of information through words, text, images, digital data, graphs, tables and so on. Information in the broadest sense is a general scientific concept that includes the exchange of signals between humans and technical devices, animate and inanimate nature.

In today's dangerous world, the Internet, the various forms of destructive ideas in the information disseminated through the media, and the abominable vices that negatively affect moral issues, it is clear that every conscious person is concerned. In recent times, the number of Internet-related violations and the number of people using the global network for malicious purposes has been increasing day by day. It should be noted that adolescents and early adolescents are more prone to the negative effects associated with the Internet. This is because the main psychological aspects of this age group are characterized by the high level of formation of the image of "l" and the fact that he tries to show his "l" among the relatives of his peers. If a teenager's "I" is not accepted, he or she will feel rejected and will try to find teenagers who are like him or her. Adolescents begin to observe their personal characteristics as early as adolescence, when they have the ability to express themselves everywhere. During adolescence, self-esteem increases, a number of questions arise, such as self-worth, what one is able to do, and what one is worth, and as one seeks answers to those questions, one is exposed to various influences. In this case, the behavior of adolescents can be assessed in terms of two methods:

- First, the adolescent evaluates the results of his / her achievements. For example, a teenager does not lose himself in a difficult situation or saves a young child from a fire - he says, "I'm not a coward". Performs a certain difficult task. "I'm talented", he said. Such moral behavior is also a test of a teenager's selfdetermination;

- secondly, a social comparison, that is, a comparison of other works and opinions about oneself.

As a result, misleading electronic publications and immoral videos are becoming more widespread. With this, he is masterfully using the Internet with the intention of poisoning the minds of our youth. By misrepresenting themselves as "close friends", "closer than parents", "selfless help", "guiding" and "doing good to people", they are misleading young people. In fact, rather than imparting religious and secular knowledge to young people, they are flying the gang leader, the ideas of the self-guided leader (unofficial leader) and the knowledge within the quotes he teaches, to the great wealth promised from nothing. On the other hand, they are unaware that by this behavior they are pulling young people to the edge of a jar and playing someone's drums. This, in turn, misleads young people and ultimately turns them into an evil force against society.

MATERIALS AND METHODS 
The role of the environment, people and society in the formation of the adolescent's personality is very big. For example, it means that in any neighborhood there are five hundred specific social environments that actively influence the composition of the adolescent. This begs the question: "How does the external environment affect the composition of adolescents?":

first, various events in the social environment have a direct effect on the human mind, leaving a deep imprint on it;

second, it is man himself who contributes to the deeper and stronger influence of the external social environment. It is well known that children, by their very nature, are imitative from an early age to the end. Children imitate these behaviors, good and bad, by directly imitating all the behaviors of adults. In the family, on the street, children secretly watch every action and interaction of adults.

Speaking about the role of the external social environment in the formation of the human personality, it should be noted that some supernatural phenomena fully confirm the crucial role of the external environment in the formation of the human personality. We are referring to the phenomenon of human children falling into the wild in some random cases. Although such events are very rare in life, they do occur in any case. For example, Dr. Sing from India sees two human cubs running on all fours along with wolf cubs in a forest near Calcutta. He then lurks at them, finds their abode, and takes the children. He names one of them Amala and the other Kamala. It is characteristic that children did not differ from wolves in terms of behavior and actions because they were exposed to wolves from an early age. There was no speech, which meant that thinking was extremely limited. This phenomenon fully confirms that in order for a person to develop as a person, he must first have a human environment, that is, a social environment.
The second factor influencing a person and his psychology is the influence of education. It is known that education shapes the human mind, its worldview, beliefs, attitudes to life. If the content of children's spiritual development and personal characteristics depended only on the external social environment, education itself, then we are equally artificial and by organizing exactly the same system of education, we would cultivate individuals who were welldeveloped in all respects and had almost the same personal characteristics. However, this cannot be the case. It should be noted that the influence of education on the formation of the child's personality is primarily understood as education in kindergartens, schools, boarding schools, lyceums and colleges. However, the education of the child in the family is not an exception. In addition to the general social environment in the family, the role of family education is also important. Examples can be given to families that are systematically engaged in child rearing and not engaged at all. In addition to the two factors mentioned above, there is a third factor that is hereditary. What is inherited from a person? Humans are inherited some anatomical and biological features. For example, body composition, hair and eye color, voice, speech style, some movements can be innate. But it must never be forgotten that man is never inherited by means of his mental qualities, that is, the qualities which are connected with his mental aspects. In extremely rare cases, certain skills, such as music and math skills, can be inherited. When we talk about the content of a person's spiritual development and personal characteristics, we need to focus on another important thing. Nowadays, we often use the term acceleration. So what is acceleration? Acceleration - (Latin acceleratio - acceleration). Today, we are witnessing the rapid development of children, both physically and mentally. So what could be the reason for this? Of course, there are different opinions on this. Some scientists are trying to 
explain the reason for the acceleration in connection with scientific and technological progress. According to them, the rapid development of science and technology puts before humanity the need to understand and process an unprecedented amount of information. This demand, in turn, led to the rapid development of man in all respects, that is, both physically and mentally. According to the above-mentioned scientists, acceleration is a phenomenon typical of the second half of the twentieth century. Also, any information obtained from the internet today cannot be accurate, reliable and harmless. In the current pandemic situation, not all of the recommended treatments for Covid-19 are effective. This is because the various information provided or promoted and disseminated by bloggers leads to various misunderstandings among the population, especially young people, withdrawal from a healthy lifestyle, and indifference to the disease.

Anyone who enters the world of the Internet without borders must always remember that time and life are a treasure. After all, this global network has endless areas where a person can get lost and spend their days inefficiently. In today's era of intense globalization, effective and reliable protection of the minds of young people from harmful ideas and influences coming through the Internet is becoming increasingly important. This requires teachers, propagandists, parents to be more prudent and careful, to further expand the scope of work to strengthen the ideological immunity of the younger generation.

We know that many sites and networks have been filtered for large sums of money, and this situation can be observed in many countries. Of course, it can be difficult and only temporary to protect people from dangerous threats, unnecessary and negative information from various forces in the Internet world through bans or filtering tools. Today, information is coming in so much and so fast that it takes deep thinking and a broad outlook to "digest" it. Such examples can be given about some computer games, especially in today's world, where the Internet is attracting the attention and interest of our youth. According to experts, 49 percent of computer games distributed over the Internet have a significantly violent and vicious appearance, while 41 percent of militant (based on various shootings and explosions) games use such violence and evil to achieve the protagonist's goal. In 17 percent of games, that violence and evil itself is the main goal. We cannot say that such games, which are different from the combat, do not fit into our mentality (lat. Mentalismental), and sometimes turn into heroic savagery, can have a direct impact on the moral and aesthetic upbringing of our children. While they may seem like a simple game at first glance, there are plenty of reallife examples of how violent ideas can lead to a lot of negative consequences.

Nowadays, the influx of various destructive ideas aimed at capturing the hearts and minds of young people is becoming more and more noticeable, especially through the internet. This process is also associated with the growing interest of our children in computer technology, various computer games. Proponents of destructive ideas are trying to use their interests to their advantage. In other words, extremists, who are well aware that "gambling" is a threat to a certain segment of society, are trying to capture the minds of teenagers and young people in this way. This can be explained by:

an increase in the amount of time a teenager spends playing;

previous habits, narrowing the scope of interests, thinking more about the game;

not being able to get out of the game whether he wins or loses; 
looking forward to the start of a game, feeling anxious and nervous when left without a game;

the desire to play more and more, to go more and more into the game;

inability to stop himself from the game.

"Okay, I quit the game", he says, but when he sees his teammates who have played together before, when he talks about the game, he quickly loses his temper as he walks past the stadium;

lying, stealing to get money from his parents for a game; The fact that he hides his excessive playfulness and lies from family members, doctors, and others is evidence of the adolescent's playfulness" [2].

\section{RESULT AND DISCUSSION}

It is clear that a lack of a serious approach to upbringing during adolescence, indifference to the behavior of the child, in many cases can lead to the loss of the child.

Currently, the information that websites have a strong impact on adolescents can be classified as follows:

the first category of information includes alien, destructive ideas (ideas of religious extremism and terrorism, nationalism, racism, sadism, etc.);

The second category of information promotes habits and skills typical of the Western way of life, contrary to the Uzbek mentality. This is especially evident in the clothing, clips, films that promote the dress and habits of western youth;

the third category includes pornographic information;

and the fourth category may include various offensive information that has not yet been verified and has not been proven.

The fact that such alien ideas and information spread on the Internet are accepted by young people and its consequences are of concern to the people of all countries of the world.

We must always be vigilant against any actions aimed at capturing the consciousness of our youth, against our national interests, against the selfish forces that are trying to influence the psyche of our youth through consciousness. That is how no one, nothing can turn us back from the path we have chosen, and we will surely achieve our glorious goals.

Of course, the potential of the Internet is not only reflected in the negative aspects, but also has its own positive aspects. These include the immediate availability of information on the Internet, the diversity of information and data, the availability of communication opportunities that help a person to express himself, the possibilities of education. While not denying the positive aspects of the Internet, it should also be noted that it has the potential to carry out effective destructive activities among young people at the lowest cost. Every day different social networks (Facebook, MySpace, Twitter, Habbo Hotel, Friendster, Tagged.com, Instagram, WhatsApp, GAP, Linkedin, On Odnoklassniki", "Live Magazine","V kontakte","V krugu druzey", “My world”, etc.) billions of people interact with each other virtually, visit various sites, visit video hosting sites such as YouTube, various bloggers express their opinions and get acquainted with the opinions of others. Given that young people are not yet fully immune to destructive ideas, and that they are very quick to believe what they hear or read, this is a process that needs a lot of attention. The concept of "information-disruptive factor" is now used by psychologists. Indeed, subversive information on the Internet can sometimes be more effective than military action. In particular, the aspects of this information that may affect the individual are as follows: 
informational pressure, aggression aimed at deliberately changing people's moral and psychological state, worldview, political views and beliefs;

dissemination of inaccurate, deliberately distorted, misleading information and data;

striving to ensure that the right information is misunderstood by people.

\section{CONCLUSION}

In conclusion, it can be said that psychological influences have a negative effect on a teenager and his behavior affects the ability to prevent the transmission of destructive information, to ensure that accurate and reliable information is misunderstood by people at this age. The media is one of the factors that causes any idea to spread quickly. From the above considerations, it can be concluded that the role and place of ideological factors in the development of the individual and the upbringing of a harmoniously developed person is important. When a child is born, he certainly relies on someone and imitates someone in shaping his worldview. Only a person who does not have access to any destructive information that affects human life can grow up to be a perfect human being in society.

\section{REFERENCES}

1. Law of the President of the Republic of Uzbekistan dated September 14, 2016 No. 406 "On state youth policy".

2. Shavkat Mirziyoev Let's be more united and resolute in the path of destiny and future of our country - T.: Uzbekistan 2017. - P 21.

3. Krol Ed. All about Internet: Manual and catalog / translation from English Timacheva C.M. - Kiev: BNV, 1995. - P. 19.

4. https://www.mover.uz

5. An explanatory dictionary of basic concepts of spirituality. - T.: Ghafur Ghulam Publishing House - T.: 2016. - P 445.
6. Speech by Sh.M.Mirziyoev at the solemn ceremony dedicated to the 25th anniversary of the adoption of the Constitution of the Republic of Uzbekistan. Internet https // uzreport.nevs <society> constitution. (application dated 15.02.2020).

7. Resolution "On approval of the concept of educating young people in the spirit of military patriotism" 2018 February 23 PQ 140. 